\title{
Three-step Crystallization in Synthesis of ZSM-5 without Organic Template
}

\author{
Hartati $^{1,{ }^{*}}$, Alfa Akustia ${ }^{1}$, Indra Permana ${ }^{1}$, Didik Prasetyoko ${ }^{2}$ \\ ${ }^{1}$ Department of Chemistry, Faculty of Science and Technology, Universitas Airlangga, Surabaya, 60115, \\ Indonesia \\ ${ }^{2}$ Department of Chemistry, Faculty of Mathematics and Sciences, Institut Teknologi Sepuluh Nopember, \\ Surabaya 60111, Indonesia \\ *Email: hartati@fst.unair.ac.id
}

\begin{abstract}
ZSM-5 was synthesized without organic template through three steps crystallization by adding seed solution. ZSM-5 crystals was characterized by X-ray diffraction (XRD), Fourier Transform Infrared (FTIR) spectroscopy and nitrogen adsorption/ desorption technique. XRD and FTIR showed that this method produced the ZSM-5 and quartz as byproduct. Nitrogen adsorption/desorption technique was as certained the formulation of micro-meso porosity of hierarchical ZSM-5.
\end{abstract}

Keywords : ZSM-5, without organic template, micro-meso porosity

\section{Introduction}

Commonly, ZSM-5 is synthesized through the addition of organic template as organic structure-directing agent (SDA), namely TPAOH (Xue [1]; Wang [2], Zhu [3]; Tao [4]) or TPABr (Xiao [5]; Pan [6]; Schmid [7]). Prasetyoko [8] synthesized pure ZSM-5 from rice husk ash with the addition of silicalite- 1 through the crystallization at $175^{\circ} \mathrm{C}$ for 24 hours. Pan [6] studied the synthesis of ZSM-5 from dealuminated metakaolin with crystallization at $180^{\circ} \mathrm{C}$ for 72 hours organic template free. The results as well as ZSM-5 synthesized by using TPABr as a template.

Hence, much research has been directed to develop ZSM-5 synthesis method by the gradual crystallization. Kim [9] reported that ZSM-5 can be observed without the addition of the organic template through a two-step process of crystallization. Crystallization at high temperature $\left(190{ }^{\circ} \mathrm{C}\right)$ were intended to accelerate the nucleation and crystallization at a lower temperature $\left(150{ }^{\circ} \mathrm{C}\right)$ that aims to control the size of crystals and crystal size distribution. The results showed a rapid nucleation and crystallization at high temperatures can form large crystals. Xianliang [10] also studied about the control of crystallization condition, at temperature of $150{ }^{\circ} \mathrm{C}$ and $190{ }^{\circ} \mathrm{C}$. They added a nucleation solution before crystallization. The results showed that crystal of ZSM5 is formed if nucleation solution is made at high temperature $\left(190^{\circ} \mathrm{C}\right)$ and crystallization is done at a lower temperature $\left(150^{\circ} \mathrm{C}\right)$ with mole ratio of $\mathrm{SiO}_{2} / \mathrm{Na}_{2} \mathrm{O}<0.18$. The lower mole ratio of $\mathrm{SiO}_{2} / \mathrm{Na}_{2} \mathrm{O}>0,18$ produced a mordenit materual. Mostafa [11] synthesized ZSM-5 without organic template by gradual crystallization at $180-^{\circ} \mathrm{C}$ which continued at $120-^{\circ} \mathrm{C}$ and then at room temperature with the addition of ZSM-5 seed. The results showed that the ZSM-5 formed is partial microporous crystalline nanosize with high surface area. The gradual crystallization in synthesis of zeolite also intended to acquire mesoporous particles, as done by Xianliang [10] to gain a hierarchical porous zeolite $\mathrm{NaY}$ particles without organic matter as a mesoporous structure directing agent. The use of organic template and organic species as mesophase directing agent (usually use hexadecyltrimethyl ammonium bromide (CTAB)) have many problems, such as high production costs and the results of thermal decomposition of the species can cause environmental pollution.

In this study, we use three step crystallization in the synthesis of ZSM-5 using seed solution without the addition of an organic template. The results obtained are compared with the synthesis without seed solution and hierarchical ZSM-5 which was synthesized using TPAOH as organic template and $\mathrm{CTAB}$ as mesophase directing agent.

5th International Conference and Workshop on Basic and Applied Sciences (ICOWOBAS 2015)

AIP Conf. Proc. 1718, 060002-1-060002-8; doi: 10.1063/1.4943324

(C) 2016 AIP Publishing LLC 978-0-7354-1364-1/\$30.00 